\title{
The prevalence of pediculosis capitis in Makkah city Saudi Arabia
}

\section{Luai Mohammed Assaedi', Aymen Hamed Alharbi ${ }^{2}$, Shahad Mahmoud Aldor', Bilqis Ahmed Albarakati', Imtinan Khalid Alsahafi', Rami Fawzi Magliah', Ghaida Bakor Alahmadi', Bassam Hussain Bugis'}

\author{
${ }^{1}$ Umm AlQura University, Makkah, Saudi Arabia, ${ }^{2}$ King Abdulaziz Hospital, Makkah, Saudi Arabia
}

Corresponding author: Dr. Aymen Hamed Alharbi, MD, E-mail: aymen334@hotmail.com

\begin{abstract}
Background: In Saudi Arabia, there is limited data regarding the epidemiology of head lice. We aim to measure the prevalence of head lice particularly in Makkah city along with assessing the risk factors associated with it. Material and Methods: A descriptive cross-sectional survey was conducted from $1^{\text {st }}$ of June to $1^{\text {st }}$ July 2017 , among all males and females with no age restriction living in the city of Makkah, Saudi Arabia. Results: Of the 438 participants (mean age, 25) the majority were female $78.5 \%$ (344), and 21.5\%(94) were male. The prevalence of P. capitis infection was $64.2 \%$ (281/438) among them $85.8 \%$, (178/281) confirmed transition of disease to another family member mainly to their sisters. The prevalence of pediculosis was significantly elevated among females $88.3 \%$ (248) than males $11.7 \%$ $(\mathrm{p}<0.0001)$. Also, it was higher among the nonemployees 82.6\%(232/281) $(\mathrm{p}<0.015)$. The infestation was significantly associated with long hair $\mathrm{p}<0.0001 .71 .2 \%$, participants with a history of lice infestation confirmed sharing personal belongings with others $(\mathrm{p}<0.0001)$. Conclusion: The infected participants were predominantly females, with a sizeable proportion confirming transition of infestation to another family member. P. capitis was commonly associated with long hair and higher among nonemployee and those who share their personal belongings.
\end{abstract}

Key words: Head lice; Pediculosis capitis; Hair disorders; Makkah

\section{INTRODUCTION}

The close relationship between lice and human is explained by a long history back to approximately 100,000 years ago. With early human migrants from Africa where they found that $P$. humans show a genetic evidence of expansion from Africa. This was evidenced by the oldest human head louse nit that was found from a hair sample dated to 8000 B.C. in northeastern Brazil; another oldest hair sample was found 9000 years old, obtained from a corpse found in the Nahal Hemar cave [1].

There are two types of lice parasitizing humans: Pthirus and Pediculus. The latter one caused a significant public health problem, and it has two ecotypes: the body louse and the head louse, where head lice diverge into three clades (A, B and C), each clade has a unique geographic distribution throughout the world [2].

P.hummanus var. capitis is an infestation of human hair, scalp, and neck by the head louse. An obligatory bloodfeeding ectoparasite, transmit by sharing personal belongings like head scarfs, brushes, pillows or even head to head contact which is the most common mode of transmission [2].

They cause blood loss, itchiness, redness, discomfort, social and psychological distress. Usually, the most common symptom of head lice is pruritus; Although head lice do not transmit any disease the possibility of secondary bacterial infections occurring at scratch sites with impetiginization [3].

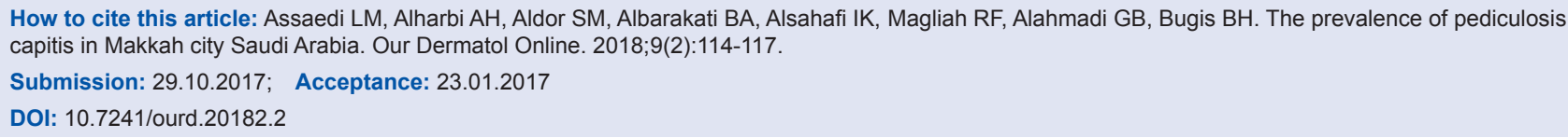


According to many studies, head lice are considered one of the common infection in school-age children all around the world [4]. Annually in the United States of America, Pediculosis capitis, affects six to twelve million individuals. In Saudi Arabia, some studies were reported but with a limitation in the data regarding the epidemiology of head lice.

In a recent study in Jeddah city, the prevalence of pediculosis was $11.26 \%$, and distribution of infestation among males and females was broadly similar [5]. In Abha city, the most common transmissible skin diseases were P. capitis (9.6\%) with an increase in the prevalence as the age decreases [6].

In our study, we aim to measure the prevalence of head lice in Makkah city among all ages. Additionally, the effect of risk factors associated with head lice.

\section{MATERIALS AND METHODS}

It is a Descriptive cross-sectional survey that was successively conducted from $1^{\text {st }}$ of June to $1^{\text {st }}$ July 2017 , Among All males and females with no age restriction living in the city of Makkah, Saudi Arabia. We included all Makkah residents who participated in the survey and excluded all non-Makkah residents from the study.

After seeking the approval from the institutional review board (IRB) of King Abdulaziz Hospital, Makkah, Saudi Arabia. An electronic questioner was created using google docs and was distributed. The survey included an overall information about the previous occurrence of pediculosis capitis, demographics and risk factors such exposure to animal pets and sharing personal belongings.

\section{Statistical analysis}

After importing the data from the Microsoft Excel file, the data was analyzed using Statistical Package for the Social Science SPSS version 23. Frequency tables were made to measure the prevalence of each variable. The risk factors were analyzed by chi-squares to measure its significances in relation to the primary dependent variables and to sit the P.value to be $=0.05$

\section{Ethics statement}

This manuscript describes original work and is not under consideration by any other journal. All authors approved the manuscript and this submission, also all the authors made significant contribution to the study.

\section{RESULTS}

A total of 438 participants were included in the analysis. The average age of participant was 25 years. $78.5 \%$ (344) of them were female, and 21.5\% (94) were male. The overall prevalence of $\mathrm{P}$. capitis infection was found to be positive in $64.2 \%$ (281/438). The prevalence of pediculosis was significantly elevated among females $88.3 \%$ (248) than males $11.7 \%(\mathrm{p}<0.0001)$. Also, it was higher among the nonemployees $82.6 \%(232 / 281)$ in comparison to the employees $17.4 \%(49 / 281)$ $(\mathrm{p}<0.015)$.

On the contrary, no significant association between head lice infection and having a pet or animal at home $(p>0.414)$, or any other demographic data (Table 1).

As for the frequency of hair washing three times a week it was higher among those who previously had head lice $51.6 \%(145 / 281)(\mathrm{p}=0.033)$.

Regarding the type and length of hair, both oily and long hair were great in association with head lice accounting for 39\% (112/281) and 59.9\% (168/281) respectively. However, only hair length showed a significant association with head lice infestation $\mathrm{p}<0.0001$ and not so much with the type of hair (Table 2).

From the 281 people with lice 241 confirmed transition of infection to another family member by $85.8 \%,(178 / 281) 63.3 \%$ were their sisters $(\mathrm{p}<0.0001)$. However, $97,9 \%$ (275 out of 281 ) denied transition of

\begin{tabular}{lccc} 
Table I: Demographic data & & \\
\cline { 1 - 2 } variables & \multicolumn{2}{c}{ Previous head lice } & \multirow{2}{*}{ P value } \\
\cline { 2 - 3 } & Yes (\%) & No (\%) & \\
\hline Sex & $33(11.7)$ & $61(38.9)$ & $0.000^{* *}$ \\
$\quad$ Male & $248(88.3)$ & $96(61.1)$ & \\
$\quad$ Female & & & \\
Are you employed? & $49(17.4)$ & $42(26.8)$ & $0.015^{\star}$ \\
$\quad$ Yes & $232(82.6)$ & $115(73.2)$ & \\
$\quad$ No & & & \\
How many family members? & $5(1.8)$ & $4(2.5)$ & 0.687 \\
2 & $13(4.6)$ & $10(6.4)$ & \\
3 & $30(10.7)$ & $20(12.7)$ & \\
4 & $233(82.9)$ & $123(78.3)$ & \\
$>4$ & & & \\
Where do you live? & $184(65.5)$ & $109(69.4)$ & 0.231 \\
$\quad$ Owned & $97(34.5)$ & $48(30.6)$ & \\
Rented & & & \\
Presence of animals/pets & $36(12.8)$ & $22(14.0)$ & 0.414 \\
$\quad$ Yes & $245(87.2)$ & $135(86.0)$ & \\
$\quad$ No & & & \\
\hline
\end{tabular}


infection to another site in their body rather than their head $(\mathrm{p}<0.0001)$.

Also, $71.2 \%$, participants with a history of lice infestation confirmed sharing personal belongings with others $(\mathrm{p}<0.0001)$ while around $40 \%$ share their bed with others $(\mathrm{p}=0.021)$.

Scalp itchiness and redness were the major significant symptoms for head lice infestation $(\mathrm{p}<0.0001$ and $\mathrm{p}=0.011)($ Table 3).

\begin{tabular}{|c|c|c|c|}
\hline \multirow[t]{2}{*}{ variables } & \multicolumn{2}{|c|}{ Previous head lice } & \multirow[t]{2}{*}{$P$ value } \\
\hline & Yes (\%) & No (\%) & \\
\hline \multicolumn{4}{|c|}{$\begin{array}{l}\text { How many times do you wash your } \\
\text { hair weekly? }\end{array}$} \\
\hline Three times & $145(51.6)$ & $60(38.2)$ & $0.033^{*}$ \\
\hline Daily & $86(30.6)$ & $67(42.6)$ & \\
\hline Less than three times & $50(17.8)$ & $30(19.1)$ & \\
\hline \multicolumn{4}{|l|}{ Hair type } \\
\hline Curly & $31(11.0)$ & $20(12.7)$ & 0.551 \\
\hline Dry & $110(39.1)$ & $51(32.5)$ & \\
\hline Dily & 112 (39.9) & $67(42.7)$ & \\
\hline Straight & $28(10.0)$ & $19(12.1)$ & \\
\hline \multicolumn{4}{|l|}{ Hair length } \\
\hline Long & $168(59.8)$ & $64(40.8)$ & $0.000^{\star *}$ \\
\hline Short & $112(39.9)$ & $93(59.2)$ & \\
\hline
\end{tabular}

Table 3: Infectious data

\begin{tabular}{|c|c|c|c|}
\hline \multirow[t]{2}{*}{ Variables } & \multicolumn{2}{|c|}{ Previous head lice } & \multirow[t]{2}{*}{$P$ value } \\
\hline & Yes (\%) & No (\%) & \\
\hline \multicolumn{4}{|l|}{ Itchy scalp } \\
\hline Yes & $126(44.8)$ & $44(28.0)$ & $0.000^{* *}$ \\
\hline No & $155(55.2)$ & $113(72.0)$ & \\
\hline \multicolumn{4}{|c|}{ Redness in the scalp } \\
\hline Yes & 39 (13.9) & $10(6.4)$ & $0.011^{*}$ \\
\hline No & $242(86.1)$ & $147(93.6)$ & \\
\hline \multicolumn{4}{|c|}{$\begin{array}{l}\text { If yes, has another family member } \\
\text { been infected? }\end{array}$} \\
\hline Yes & $241(85.8)$ & $1(.6)$ & $0.000^{* *}$ \\
\hline No & $39(13.9)$ & $0(0.0)$ & \\
\hline \multicolumn{4}{|c|}{ If yes, what is kinship? } \\
\hline Brother & 39 (13.9) & $3(1.9)$ & $0.000^{* *}$ \\
\hline Father & $3(1.1)$ & $0(0.0)$ & \\
\hline Mother & $15(5.3) 0$ & $0(0.0)$ & \\
\hline Sister & $178(63.3)$ & $12(7.6)$ & \\
\hline \multicolumn{4}{|c|}{$\begin{array}{l}\text { Did infection move to another place } \\
\text { rather than your head? }\end{array}$} \\
\hline Yes & $6(2.1)$ & $0(0.0)$ & $0.000^{* *}$ \\
\hline No & 275 (97.9) & $0(0.0)$ & \\
\hline \multicolumn{4}{|c|}{$\begin{array}{l}\text { Sharing personal belonging with } \\
\text { other }\end{array}$} \\
\hline Yes & $200(71.2)$ & 84 (53.5) & $0.000^{* *}$ \\
\hline No & $81(28.8)$ & $73(46.5)$ & \\
\hline \multicolumn{4}{|c|}{ Sharing beds at home } \\
\hline Yes & $115(40.9)$ & $45(28.7)$ & $0.021^{*}$ \\
\hline No & $165(58.7)$ & $112(71.3)$ & \\
\hline
\end{tabular}

\section{DISCUSSION}

There are Important factors affecting the rate of infestation by head lice, such as socioeconomic factors, personal hygiene, and gender. Some of them have been approved previously by researchers to contribute to the transition of lice from head-to-head which we included in our research. The rate of infestation in unemployed people were higher at different ages by $82.6 \%$ comparing to the employees. Which reveals that people of low income can somehow be more prone to infestation, this finding has been approved as well in Korea where they found that even the occupation of parents can affect the prevalence of head lice [7]. We wanted to elaborate further on the income side by asking about the ownership of their property whether it was rented or owned. However, the majority responded by owned which caused a low sensitivity in the desired result. On the other hand, the rate of infestation increased among bigger families which known to lower the income, 233 previously infected people said to live amongst a large family of more than four household members.

The rate of infection is primarily affected by personal hygiene. In our case, the type of hair and length which require more effort and care had a significant impact on both the prevalence and rate of infestation. In our study, the rate of infestation encompassed $59.8 \%$ in those with long hair and oily hair by $39.9 \%$. In the analysis of data, the girls over twelve years of age in Sindh province of Pakistan indicated that infrequent bathing in summer was associated with higher rates of infestation in Sindh province which shows the importance of hygiene when it comes to lice [3].

The head infestation was found to be higher among females by $88.3 \%$ than males. Also, the transition of infection from an infected person to another was higher by $63.3 \%$ among their sisters, which means that P. capitis infection has a higher rate among females. This might be explained by the nature of females and their close contact with each other, unlike males they share their headscarf accessories [8]. Again this is also was seen in our results, sharing personal belongings had a higher rate of infestation by $71.2 \%$. In many studies like the cross-sectional study that was conducted in the urban area of Athens in Greece. The overall infestation rate $(5.30 \%)$ was mainly attributed to females, which manifested a higher rate $(4.84 \%)$ than male children [9]. 


\section{CONCLUSION}

In summary, our study found out that among people who are affected by pediculosis capitis in Makkah region were mostly female. Other risk factors were the frequency of hair washing, type, and length of hair, a high number of family members, sharing personal belongings, beds, and transition of infestation between family members, in addition to employment and socioeconomic status. The results that gathered here, using a questioner reflected a lower sensitivity of this technique in relation to direct scalp examination, microscopic examination for nets, and taking hair samples from barbershops. We expect for future research to put that in consideration, also to establish the prevalence of pediculosis capitis in Saudi Arabia as well as launching educational campaigns in schools, hospitals, and public areas to increase the awareness hopefully to prevent and control head lice.

\section{REFERENCES}

1. Amina Boutellis, Laurent Abi-Rached, Didier Raoult. The origin and distribution of human lice in the world, Infect Genet Evol. 2014;23:209-17.

2. Madke B, Khopkar U. Pediculosis capitis: An update. Indian J
Dermatol Venereol Leprol. 2012;78:429-38.

3. Mahmud S, Pappas G, Hadden WC. Prevalence of head lice and hygiene practices among women over twelve years of age in Sindh, Balochistan, and North West Frontier Province: National Health Survey of Pakistan, 1990-1994. Parasit Vectors. 2011;4:11.

4. Rassami W, Soonwera M. Epidemiology of pediculosis capitis among schoolchildren in the eastern area of Bangkok, Thailand. Asian Pac J Trop Biomed. 2012;2:901-4.

5. Al-Zanbagi NA, Al-Hashdi DF. Prevalence of Head Lice in Jeddah City, Saudi Arabia According to Crowding Criteria. Al-Zanbagi and Al-Hashdi, J Basic Appl Res. 2016;2:22-6.

6. Bahamdan K, Mahfouz AAr, Tallab T, Badawi IA, A-Amar OA. Skin diseases among adolescent boys in Abha, Saudi Arabia. International. J Dermat. 1996;35:405-7.

7. Sim S, Lee W-J, Yu J-R, Lee IY, Lee SH, Oh SY, et al. Risk Factors Associated with Head Louse Infestation in Korea. Korean J Parasitol. 2011;49:95-8.

8. Abd El Raheem TA, El Sherbiny NA, Elgameel A, El-Sayed GA, Moustafa N, Shahen S. Epidemiological comparative study of pediculosis capitis among primary school children in fayoum and minofiya governorates, Egypt. J Community Health. 2015;40:222.

9. Tagka A, Lambrou GI, Braoudaki M, Panagiotopoulos T, Papanikolaou E, Laggas D. Socioeconomic factors associated with pediculosis (phthiraptera: pediculidae) in Athens, Greece. J Med Entomol. 2016;53:919-2.

Copyright by Luai Mohammed Assaedi, et al. This is an open-access article distributed under the terms of the Creative Commons Attribution License, which permits unrestricted use, distribution, and reproduction in any medium, provided the original author and source are credited.

Source of Support: Nil, Conflict of Interest: None declared. 